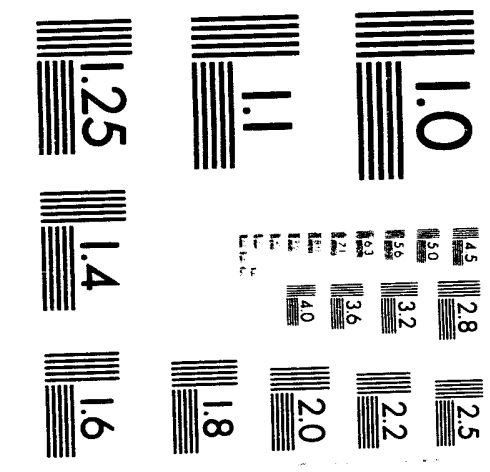


UCRL-CR-115460

\#DE-AC35-89ER 40486

\section{COMPARISON OF GAP FRAME DESIGNS AND MATERIALS FOR PRECISION CATHODE STRIP CHAMBERS}

John Horyath, LLNL

September 16, 1993

RECEIVED

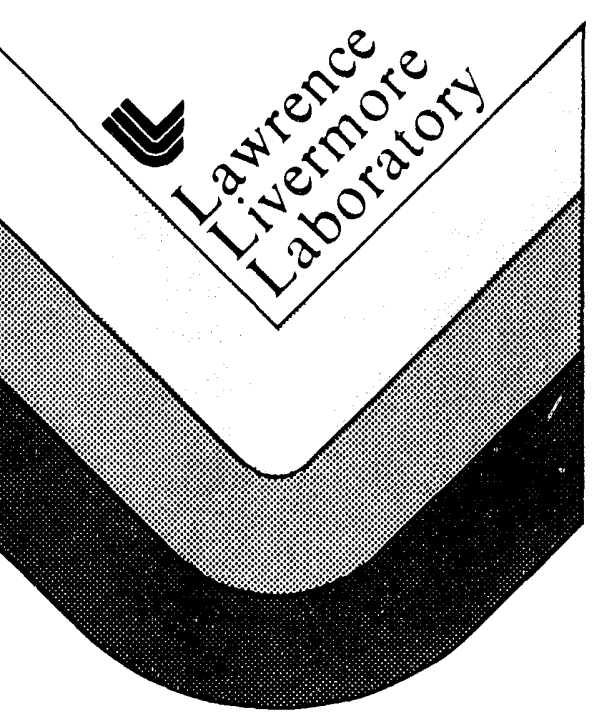

JAN 271994

\section{OSTI}




\section{DISCLAIMER}

This document was prepared as an acccount of work sponsored by an agency of the United States Government. Neither the United States Government nor the University of California nor any of their employees, makes any warranty, express or implied, or assumes any legal liability or responsibility for the accuracy, completeness, or usefulness of any information, apparatus, product, or process disclosed, or represents that its use would not infringe privately own rights. Reference herein to any specific commercial prociucts, process, or service by trade name, trademark, manufacturer, or otherwise, does not necessarily constitute or imply its endorsement, recommendation, or favoring by the United States Government or the University of California. The views and opinions of authors expressed herein do not necessarily state or reflect those of the United States Government or the University of California, and shall not be used for advertising or product endorsement purposes.

\section{AUSPICES}

Work performed under the aupices of the U. S. Department of Energy by Lawrence Livermore National Laboratoiy under contract W-7405-ENG-48. 


\title{
Comparison of \\ Gap Frame Designs and Materials \\ for \\ Precision Cathode Strip Chambers
}

\author{
John A. Horvath \\ Steven M. Pratuch \\ F. Curtis Belser \\ Lawrence Livermore National Laboratory
}

September 9, 1993

\begin{abstract}
:
Precision cathode strip chamber perimeter designs that incorporate either continuous or discrete-post gap frames are analyzed. The effects of ten design and material combinations on gravity sag, mass, stress, and deflected shape are evaluated. Procedures are recommended for minimizing mass in the chamber perimeter region while retaining structural integrity and electrical design latitude.
\end{abstract}




\section{Table of Contents}

\section{Summary, and Conclusions}

\section{Background and Introduction}

Fig. 1: Shear Deflection Due to "Slipping"

Fig. 2: Loss of Cross Section Flatness Due To Shear

3. How Chamber Structure Influences Gravity Sag

Table 1. Effectiveness of Chamber Components In "Pure Bending"

4. Evaluation of Materials

Fig. 3: Beam Used for Material Comparisons

Table 2. Material Comparison

5. Comparison of Continuous and Discrete-Post Gap Frames

Fig. 4: Quarter-Symmetric Finite Element Model

Fig. 5: Displacements x $5(1)$ for Case "A" (Normalization Baseline)

Table 3. Comparison of Gap Frame Designs and Materials

Fig. 6: Displacements $x 500$ for Case " $\mathrm{H}$ " Showing Loss of Gap Uniformity

Fig. 7: Moments and Shear Forces In End-Region Gap Frame

Fig. 8: Displacements $x$ 5(K) for Case " $B$ "

Fig. 9: Displacements $\times 500$ for Case "J"

6. Continuous Gap Frame Details

Fig. 10: Isometric View of Continuous Gap Frame

7. Discrete-Post Gap Frame Details

Fig. 11: Isometric View of Discrete-Post Gap Frame

Fig. 12: Cross Section of Stack of Panels With Post

Fig. 13: Cross Section of a Discrete Post

Fig. 14: Layout of Perimeter Electronics for Outer Superlayer CSC

Fig. 15: Cross Section "A-A" Through Edge Connector

8. Loads and Stresses

Fig. 16: Load and Shear Force Distribution

9. Practical Considerations

10. Design Recommendations

Fig. 17: Cross Section of Recommended Edge Design

\section{Further Design and Analysis Tasks}




\section{Summary, and Conclusions}

The following key points summarize this paper:

- The reductions in chamber mass achieved by incorporating small, discrete posts in the gap frame design evaporate when we restore the lost shear stiffness by appropriate sizing of the posts.

- Alternative material choices incorporated in a continuous gap frame design show the most promise of achieving mass reductions without compromising chamber stiffness and without increasing design complexity. Materials having high stiffness-to-density ratios are needed only for load-bearing locations (under bolts, near support connections, etc.) thus requiring less material to carry a given load.

- Castable epoxies with high-modulus fillers are optimal for all load-bearing components of the gap frame region.

- Ultra-low density materials are optimal for lightly loaded components.

- An optimal cathode strip chamber gap frame design simultaneously minimizes muon scattering (mass effects), shear deformations, gravity sag, stress levels, and complexity.

In addition, from the design perspective it is important to avoid close interdependence between electrical and structural component details along the perimeter of the chamber if there is no significant mass reduction.

- The development of an optimal design for structural and electrical systems is greatly complicated if both are expected to share the same real estate (discrete posts and electrical components in the same perimeter zone).

- Separate zones along the chamber perimeter for electrical components and structural details permits flexibility during the design process to accommodate the inevitable changes in electrical component sizes and layout.

- A design incorporating a perimeter bolting pattern outside of the gap seal is easier to seal with fewer parts. The discrete-post design requires that each bolt be sealed at both ends while maintaining a proper pre-load through the chamber assembly; a difficult design task that is more expensive to implement.

\section{Background and Introduction}

An un-optimized, "continuous" gap frame design (similar to Fig. 17) was prepared for the GEM P.A.C. Review held in May 1993. This design incorporated a continuous shear connection between sandwich panels. It used bolts along the perimeter of the chamber assembly to maintain the necessary shear connection.

An alternate design was subsequently proposed (Fig. 15) which incorporated discrete posts between panels in a chamber assembly. Bolts, which passed through the center of the posts from one panel to the next, established the shear connection in the assembly. The posts were located inside the perimeter gap frame seal and shared real estate with anode electrical components in a zone along the perimeter of the chamber. The dimensions of the perimeter region of the chamber were reduced thus reducing overall mass. 
In GEM TN-93-350, Gravity Sag of Sandwich Panel Assemblies as Applied to Precision Cathode Strip Chamber Structural Design, July 12, 1993, we saw that high modulus/low density gap frames reduced gravity sag and that the honeycomb edge filler material appeared to contribute nothing to the structure (except around bolts). Howevei, the beam bending theory used in that paper also predicted that the gravity sag of a stack of seven sandwich panels would be 39 times higher if slipping occurred between panels. In other words, disrupting the shear connection around the perimeter between panels could increase total gravity sag by as much as a factor of 39 (times the beam bending prediction of approximately $1 \mathrm{~mm}$ ).

In GEM TN-93-350, we also saw that shear "slipping" between sandwich panels in the gap region results in shear deflection as well as local distortions of chamber cross sections. In "pure bending" we assume the slabs shown in Fig. la. do not slide on each other. Shear "sliding" produces the increased gravity sag seen in Fig. $1 \mathrm{~b}$.

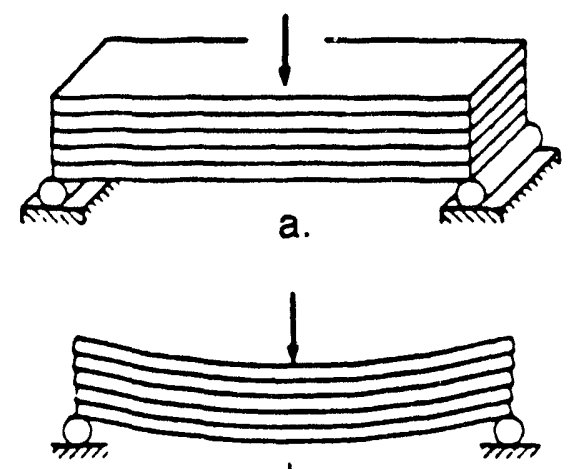

b.

Figure 1: Shear Deflection Due To "Slipping"

The portion of this "worst-case factor of 39" that occurs depends on, among other things, chamber perimeter region design and material choices. The underlying assumption of beam theory is that all beam cross sections will remain flat during gravity sag, and that even the most narrow or soft gap frame will not permit slipping between sandwich panels.

Designs meant to reduce chamber mass may also increase shear deformation. One must maintain bending and shear structural rigidity to control gravity sag when lightening the chamber. Changing from a continuous gap frame to a discontinuous, discrete-post frame removes mass from the chamber perimeter while reducing chamber stiffness. Locating these discrete posts between electronic components is possible only if sufficient space is available. The removal of material from the perimeter region must be balanced with the added shear deformations that result. Fig. 2 , taken from a finite element analysis of a structurally inadequate gap frame design, clearly illustrates the loss of cross-section flatness near a corner support point.

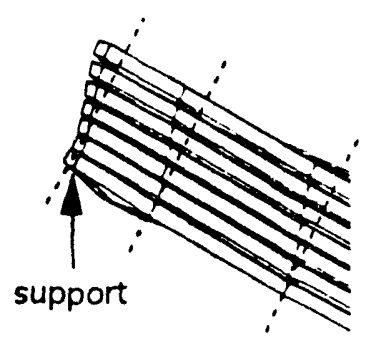

Figure 2: Loss of Cross Section Flatness Due To Shear 
This paper is a follow-up to that earlier work. We evaluate the shear deflection component of gravity sag and use it to compare the structural adequacy of chamber perimeter designs and materials. We analyze ten combinations of two perimeter designs and six materials for their effectiveness in reducing mass without compromising chamber stiffness. Material removal, relocation, or substitution are the only mass-reduction techniques considered here. We evaluate the loss in structural rigidity that occurs for these nine chamber perimeter design and material combinations and make recommendations for further optimization. (Future work will include investigation of "external" stiffening techniques.)

\section{How Chamber Structure Influences Gravity Sag}

The "ideal" chamber design has negligible shear deformation. Inadequate gap frame shear rigidity causes sandwich panels to "slip" with respect to each other as explained in the previous section. Similarly, if the panel cores are not stiff enough in shear, the skins of each panel may "slip" with respect to each other. Sandwich panel skins carry most of the structural mass in a typical chamber design. Table 1 shows the dominance of the panel skins as a bending-load carrier. The application of beam bending theory to a barrel region outer superlayer chamber with a glass-fiber filled epoxy gap frame and an unfilled-epoxy core edge filler produced the results in Table 1.

The high-modulus components, if located appropriately, will carry a larger share of the total load. Table 1 shows the mass distribution and load sharing for a chamber in "pure bending" for the material choices listed.

Table 1. Effectiveness of Chamber Components In "Pure Bending"

\begin{tabular}{|c|c|c|c|}
\hline component & $\begin{array}{c}\text { \% of total } \\
\text { chamber mass } \\
\text { added by component }\end{array}$ & $\begin{array}{c}\text { \% of total } \\
\text { chamber mass } \\
\text { carried by component }\end{array}$ & $\begin{array}{c}\text { \% of mass carried } \\
\text { minus } \\
\text { \% of mass added }\end{array}$ \\
\hline $\begin{array}{c}\text { O.5mm } \\
\text { G10 laminate } \\
\text { panel skins }\end{array}$ & $\mathbf{3 9}$ & $\mathbf{7 7}$ & $\mathbf{3 8}$ \\
\hline $\begin{array}{c}25 \mathrm{~mm} \\
\text { unfilled epoxy } \\
\text { core edge filler }\end{array}$ & $\mathbf{1 8}$ & 7 & $-\mathbf{1 1}$ \\
\hline $\begin{array}{c}25 \mathrm{~mm} \\
\text { glass-fiter/epoxy } \\
\text { gap frame }\end{array}$ & $\mathbf{1 2}$ & $\mathbf{9}$ & $-\mathbf{3}$ \\
\hline $\begin{array}{c}\text { 0.017mm } \\
\text { copper } \\
\text { cathode planes }\end{array}$ & $\mathbf{4}$ & $\mathbf{7}$ & $\mathbf{3}$ \\
\hline $\begin{array}{c}\text { 19mm Nomex } \\
\text { honeycomb } \\
\text { core }\end{array}$ & $\mathbf{1 1}$ & $\mathbf{0}$ & $\mathbf{- 1 1}$ \\
\hline $\begin{array}{c}25 \mathrm{~kg} \\
\text { hardware } \\
\text { and utilities }\end{array}$ & $\mathbf{1 6}$ & $\mathbf{0}$ & $\mathbf{- 1 6}$ \\
\hline
\end{tabular}

In an "ideal" chamher with negligible shear deflection, the panel skins carry about $77 \%$ of the load but add only $39 \%$ to the total mass. However, some results in Table 1 are deceptive. The gap frame seems to barely carry its own weight, and the Nomex honeycomb core appears to be dead 
load. These components do not play a direct role in bending stiffness, but they are the primary components of shear stiffness.

The ultimate structural effectiveness of candidate gap frame materials can be estimated in advance of any detailed analyses by using a simple beam evaluation method as shown in the next section. The finite element analyses summarized later in this paper calculate changes in shear stiffness. We then explore how much material we can safely remove from a component, and the relative importance of a component's mechanical properties.

\section{Evaluation of Materials}

In this section, we observe the following:

- High-modulus fiber-filled epoxies are superior to unfilled or ultra-low density epoxies for load-bearing applications. G10 laminate is a less desirable frame material since it has the in-plane shear properties of unfilled epoxy, requires a $250^{\circ} \mathrm{F}$ cure, and is not castable.

- Castable glass-fiber filled epoxy is the most promising of the room-temperature (R.T.) cured, electrically-insulating materials considered.

- Carbon-fiber filled epoxy is ideal as a honeycomb core edge filler where its electrical properties are acceptable.

- Ultra-low density material is ideal for lightly loaded components. The ultra-low density material evaluated here also has very low modulus. The amount of this material needed to carry a given load is larger, so the size (and mass) of higher-density components attached to it also increases.

- High-modulus low-density fibers are the most desirable epoxy fillers. Some examples are carbon, aluminum, glass, or kevlar fibers.

We know that a desirable chamber frame material has low density, high modulus, and high radiation length. However, no single parameter is meaningful in isolation. For instance, introducing bubbles into a bulk material not only reduces material density but also reduces modulus. Hence we must use more of that material to recover the lost stiffness.

The following analysis combines material density, modulus, and radiation length into $m^{*}$ values that are proportional to the deleterious mass effects of that material on the muon system. Suppose we construct the rectangular cross-section beam shown in Fig. 3 from one of the candidate materials listed below.

1. carbon-fiber filled epoxy such as Fiber-Resin FR-337 (castable, cure @ R.T.)

2. G10 woven-glass laminate such as Epoxy-Gillfab 1040 (plies, cure @ 250 F)

3. glass-fiber filled epoxy (castable, cure @ R.T.)

4. syntactic epoxy such as Ciba-Geigy 1617-A (castable, cure @ R.T.)

5. unfilled epoxy such as Fiberite 954-3 (castable, cure @ 350 of)

6. ultra-low density epoxy (precast blocks) 


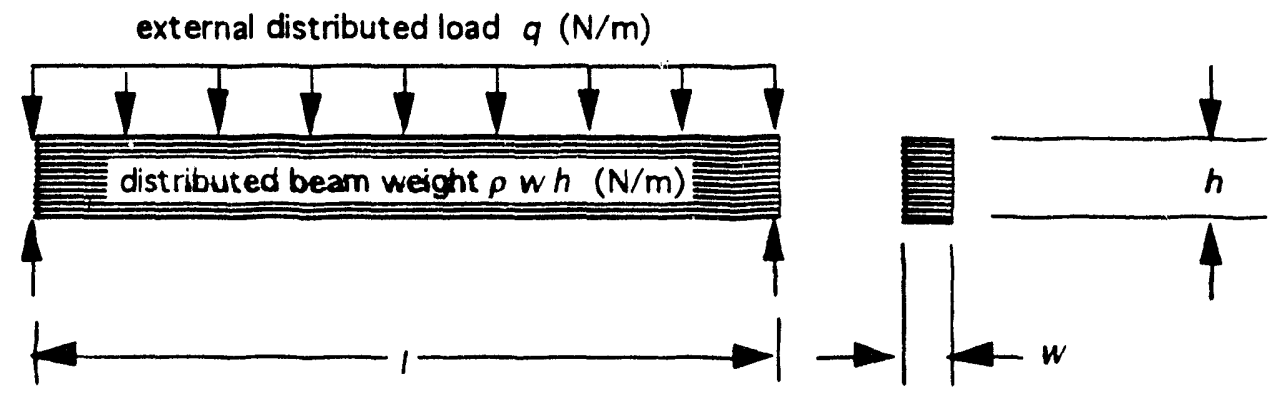

Figure 3: Beam Used For Material Comparisons

The beam carries an externally applied distributed load $q$ plus its own distributed weight $\rho w h$. The beam sag at the center due to bending is:

$$
\text { beam sag }=K \frac{(q+\rho w h)}{E w}=K 1 \frac{q}{E w}+K 2 \frac{\rho}{E}
$$

where $q$ is an external distributed load, $\rho$ is the beam density, $w$ is the beam width, $h$ is beam height, and $K, K 1$, and $K 2$ are constants which account for beam length, height, and support conditions. Each of the two load sources, $q$ and $\rho w h$, contributes to beam sag.

When the distributed load greatly exceeds the heam weight $(q>>\rho h)$, then:

$$
\text { beam sag }=K I \frac{q}{E_{W^{\prime}}}
$$

gravity sag as the baseline for normalization) divided by the radiation length, $l_{R}$, produces the parameter $m l^{*}$ which is:

$$
m l^{*}=\frac{w}{l_{R}}=\frac{E_{b} w_{b}}{E l_{R}}
$$

where the subscript $b$ denotes the properties used for the baseline for normalization. The parameter $m l^{*}$ (small for a beam with low width and high radiation length) is a valid indicator when the distributed load greatly exceeds the beam weight $(q>>\rho w h)$.

When the beam weight greatly exceeds the distributed load $(\rho w h>>q)$, then:

$$
\text { beam sag }=K 2 \frac{\rho}{E}
$$

and we reduce beam sag by minimizing $\rho / E$. The ratio of $\rho / E$ divided by the radiation length produces the parameter $m 2 *$ which is:

$$
m 2 *=\frac{\rho}{E l_{R}}
$$

where $m 2 *$ (small for a beam with low density, high modulus, and high radiation length) is a valid indicator if the beam weight greatly exceeds the distributed load ( $\rho w h>>q)$. 
The results are summarized in Table 2 for the six materials. (Quantities normalized are with respect to G10 laminate.)

Table 2. Material Comparison

\begin{tabular}{|c|c|c|c|c|c|c|}
\hline & $\begin{array}{c}\text { carbon-fiber } \\
\text { filled epoxy } \\
\text { FR-337 } \\
\text { cure @ R.T. }\end{array}$ & $\begin{array}{c}\text { G10 } \\
\text { taminate } \\
\text { E-G 1040 } \\
\text { cure @ 250F }\end{array}$ & $\begin{array}{c}\text { chopped } \\
\text { glass-fiber } \\
\text { filled epoxy } \\
\text { cure @ R.T. }\end{array}$ & $\begin{array}{c}\text { syntactic } \\
\text { epoxy } \\
1617-A \\
\text { cure @ R.T. }\end{array}$ & $\begin{array}{c}\text { unfilled } \\
\text { epoxy } \\
\text { F-954-3 } \\
\text { cure @ 350F } \\
\end{array}$ & $\begin{array}{l}\text { ultra-low } \\
\text { density } \\
\text { epoxy } \\
\text { precast blocks }\end{array}$ \\
\hline $\begin{array}{c}\rho \\
\text { density } \\
\mathrm{g} / \mathrm{cm}^{3}\end{array}$ & 1.66 & 1.93 & 1.85 & 0.70 & 1.19 & 0.42 \\
\hline $\begin{array}{l}\mathrm{E} \\
\text { modulus } \\
\mathrm{MPa} \text { [ksi] }\end{array}$ & $\begin{array}{l}34,500 \\
{[5,000]} \\
\end{array}$ & $\begin{array}{l}22,760 \\
{[3,300]}\end{array}$ & $\begin{array}{r}11,030 \\
{[1,600]} \\
\end{array}$ & $\begin{array}{l}2,410 \\
{[350]}\end{array}$ & $\begin{array}{l}2,760 \\
{[400]}\end{array}$ & $\begin{array}{c}680 \\
{[100]}\end{array}$ \\
\hline $\begin{array}{c}l_{R} \\
\text { radiation length } \\
\mathrm{cm} \\
\end{array}$ & 34.0 & 19.4 & 21.2 & $\begin{array}{c}56-66 \\
(?)\end{array}$ & 55 & $\begin{array}{c}91-107 \\
(?)\end{array}$ \\
\hline $\begin{array}{c}\text { normalized } \\
\rho / E\end{array}$ & 0.57 & 1.00 & 1.98 & 3.43 & 5.10 & 7.20 \\
\hline $\begin{array}{c}\text { required } \\
\text { width } \\
\left(q \gg>\rho w^{\prime} h\right)\end{array}$ & 0.66 & 1.00 & 2.06 & 9.43 & 8.25 & 33.0 \\
\hline $\begin{array}{c}\boldsymbol{m} \mathbf{l}^{*} \\
\text { if } q \text { dominates } \\
\left(q>>w^{\prime} h\right)\end{array}$ & 0.38 & 1.00 & 1.89 & $\begin{array}{c}2.77 \dot{(?)}^{3.27} \\
\end{array}$ & 2.91 & $\begin{array}{c}5.98 \text { (?) }^{7.04} \\
\end{array}$ \\
\hline $\begin{array}{c}\boldsymbol{m}^{*} \\
\text { if } \rho \text { dominates } \\
(\rho w h>>q)\end{array}$ & 0.32 & 1.00 & 1.81 & $\begin{array}{c}1.01\left(^{(?)}\right. \\
\end{array}$ & 1.80 & $\begin{array}{c}1.30 \text { (?) }^{1.53} \\
\end{array}$ \\
\hline
\end{tabular}

Table 2 notes:

"Smaller is better" for values in the last four rows of Table 2.

$m l^{*}$ and required width are VALID INDICATORS IF $(q>\rho w h)$

$m 2 *$ is a VALID INDICATOR IF $(\rho w h>>q)$

(?) denotes estimates based on $50 / 50$ to $25 / 75$ mass fractions of $\mathrm{SiO}_{2} / \mathrm{Epoxy}$

The last two rows indicate that a carbon-fiber filled epoxy is at least four (1.30/0.32) times more desirable (using $m 2^{*}$ ) than an ultra-low density epoxy. The advantage exceeds a factor of fifteen $(5.98 / 0.38)$ for higher loads (using $m l^{*}$ ). Material mechanical properties and radiation lengths need additional verification.

The third row from the bottom indicates that, for load-carrying applications ( $q>>\rho w h)$, lowmodulus materials require larger widths to maintain stiffness. Therefore, choose high modulus materials for load-carriers such as the gap frame. 


\section{Comparison of Continuous and Discrete-Post Gap Frames}

Finite element analyses predict total chamber deflection that includes the bending component and the shear component of gravity sag. We isolate and evaluate the shear component of gravity sag by subtracting the ideal zero-shear bending deflection from the total deflection. Fig. 4 illustrates the quarter-symmetric finite element model used in all analyses. Each comer of the chamber is a support location. The gravity vector is normal to the chamber face.

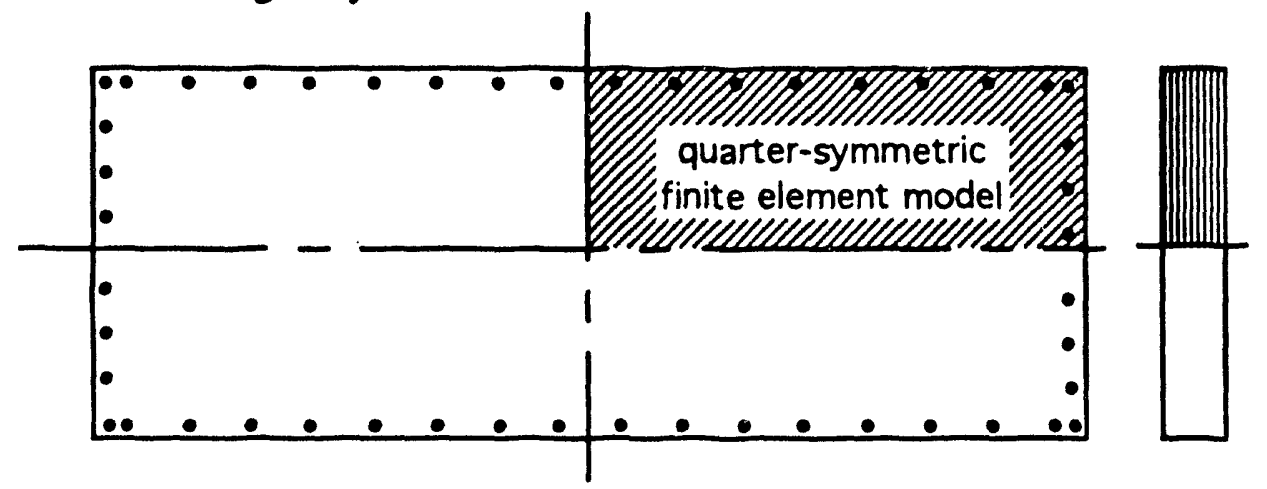

Figure 4: Quarter-Symmetric Finite Element Model

The finite element model assumes that gap frame parts are bonded such that "slipping" at part interfaces cannot occur. Movement is restricted to material distortion. The practical implementation of this assumption is achieved by bolts, friction, and/or adhesive at part interfaces.

In Table 3, case " $A$ " has a continuous glass-fiher filled epoxy gap frame located outside the electronics zone and a carbon-fiber filled honeycomb edge filler. Fig. 5 shows case " $A$ ", the baseline for normalization and the most rigid design evaluated.

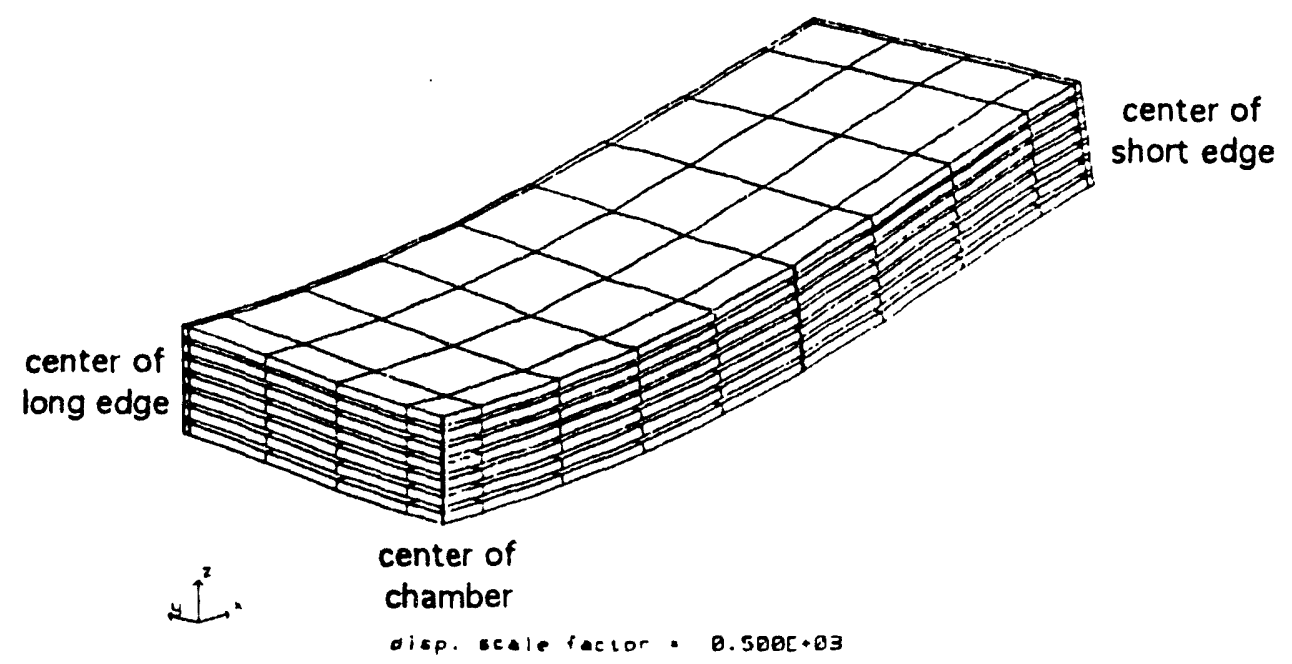

Figure 5: Displacements $\times 500$ for Case "A" (Normalization Baseline) 
Table 3 summarizes the results of finite element and beam bending gravity sag calculations.

Table 3. Comparison of Gap Frame Designs and Materials

\begin{tabular}{|c|c|c|c|c|c|c|}
\hline case & $\begin{array}{c}\text { (Note I) } \\
\text { gap frame }\end{array}$ & $\begin{array}{l}\text { (Note 2) } \\
\text { sandwich core } \\
\text { edge filler }\end{array}$ & $\begin{array}{c}\text { (Note 3) } \\
\text { normalized } \\
\text { total } \\
\text { deflection } \\
\text { of side } \\
\text { frame }\end{array}$ & $\begin{array}{l}\text { (Note 4) } \\
\text { percent } \\
\text { shear } \\
\text { deflection } \\
\text { of side } \\
\text { frame }\end{array}$ & $\begin{array}{c}\text { (Note 5) } \\
\text { normalized } \\
\text { total } \\
\text { mass }\end{array}$ & $\begin{array}{l}\text { (Note 6) } \\
\text { \% change } \\
\text { in mass }\end{array}$ \\
\hline A & $\begin{array}{l}\text { continuous } \\
\text { glass-fiber } \\
\text { filled epoxy }\end{array}$ & $\begin{array}{l}\text { continuous } \\
\text { carbon-fiber } \\
\text { filled epoxy }\end{array}$ & 1.00 & 10 & 1.00 & 0 \\
\hline B & $\begin{array}{l}\text { continuous } \\
\text { glass-fiber } \\
\text { filled epoxy }\end{array}$ & $\begin{array}{l}\text { continuous } \\
\text { glass-fiber } \\
\text { fllled epoxy }\end{array}$ & 1.48 & 16 & 1.02 & +2 \\
\hline C & $\begin{array}{l}\text { continuous } \\
\text { unfilled } \\
\text { epoxy }\end{array}$ & $\begin{array}{l}\text { continuous } \\
\text { unfilled } \\
\text { epoxy }\end{array}$ & 1.73 & 24 & 0.92 & -8 \\
\hline D & $\begin{array}{l}\text { continuous } \\
\text { ultra-low } \\
\text { density epoxy }\end{array}$ & $\begin{array}{l}\text { continuous } \\
\text { ultra-low } \\
\text { density epoxy }\end{array}$ & 1.86 & 37 & 0.81 & -19 \\
\hline$E$ & $\begin{array}{l}\text { continuous } \\
\text { ultra-low } \\
\text { density epoxy }\end{array}$ & $\begin{array}{c}\text { continuous } \\
\text { unfilled } \\
\text { epoxy }\end{array}$ & 1.82 & 30 & 0.89 & -11 \\
\hline$F$ & $\begin{array}{l}\text { continuous } \\
\text { glass-fiher } \\
\text { filled epoxy }\end{array}$ & $\begin{array}{c}\text { continuous } \\
\text { unfilled } \\
\text { epoxy }\end{array}$ & 1.67 & 21 & 0.95 & -5 \\
\hline G & $\begin{array}{l}\text { continuous } \\
\text { glass-fiber } \\
\text { filled epoxy }\end{array}$ & edge filler & 2.21 & 47 & 0.83 & -17 \\
\hline $\mathrm{H}$ & $\begin{array}{c}15 \mathrm{~mm} \times 15 \mathrm{~mm} \\
\text { discrete-post } \\
\text { glass-fiber } \\
\text { epoxy }\end{array}$ & $\begin{array}{c}\text { inter-post } \\
\text { ultra-low } \\
\text { density epoxy }\end{array}$ & 2.25 & 49 & 0.78 & -22 \\
\hline I & $\begin{array}{c}60 \mathrm{~mm} \times 15 \mathrm{~mm} \\
\text { discrete-post } \\
\text { glass-fiber } \\
\text { epoxy }\end{array}$ & $\begin{array}{c}\text { inter-post } \\
\text { ultua-low } \\
\text { density epoxy }\end{array}$ & 2.13 & 45 & 0.80 & -20 \\
\hline $\mathbf{J}$ & $\begin{array}{c}60 \mathrm{~mm} \times 15 \mathrm{~mm} \\
\text { discrete-post } \\
\text { glass-fiber } \\
\text { epoxy }\end{array}$ & $\begin{array}{l}\text { inter-post } \\
\text { carbon-fiber } \\
\text { filled epoxy }\end{array}$ & 1.04 & 18 & 0.93 & -7 \\
\hline
\end{tabular}

Table 3 notes:

1. material properties are assumed "isotropic", having the same properties in all directions

2. "discrete posts" extend through the panel ("inter-post edge filler" is between posts)

3. total deflection from finite element analyses are normalized to case " $A$ "

4. equals total deflection minus the bending component divided by the total deflection

5 . includes $25 \mathrm{~kg}$ for chamber utilities and added width for continuous gap frame cases

6 . \% change in the sum of sandwich panel, gap frame, honeycomb edge filler mass, and utilities ( $25 \mathrm{~kg}$ for all cases) 
A trend emerges as one inspects the normalized total side frame deflection and the percent change in mass for the discrete-post designs, cases " $H$ ", " $\Gamma$ ", and " $J$ ", at the end of Table 3 . As the discrete-post design is stiffened to reduce shear deflection the mass reduction becomes small. Case " $J$ ", the stiffest discrete-post design evaluated, sagged 4\% more than the baseline case " $A$ " but

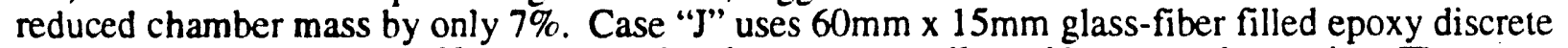
posts, the largest that could be accommodated in the space allowed between electronics. They extend through the entire thickness of the chamber as shown in Fig. 13, and have carbon-fiber filled epoxy honeycomb edge filler between them.

Comparing continuous gap frame cases " $A$ " and " $G$ " we see that removing the honeycomb edge filler material increases the total deflection by a factor of $121 \%$. Since case " $G$ " is $17 \%$ lighter than case " $A$ ", the increased sag is due to shear movement between faces of the sandwich panels. The percent-shear-deflection increases to $47 \%$ from the baseline of $10 \%$. The sandwich honeycomb cores are experiencing the added shear deformation. This suggests that during optimization we evaluate alternate honeycomb materials that exhibit better density-to-shear-modulus ratios. Shear stresses in discrete posts go up disproportionately fast since stress concentration factors of about 3.0 exist at the fillets. Creep rate is a function of stress level, therefore these high discrete-post stresses demand additional evaluation.

Shear deformations or "slipping" between sandwich panels in the gap regions also result in a degradation in gap uniformity. This effect is visible (using a displacement scale factor of 500) in case " $H$ " shown in Fig. 6.

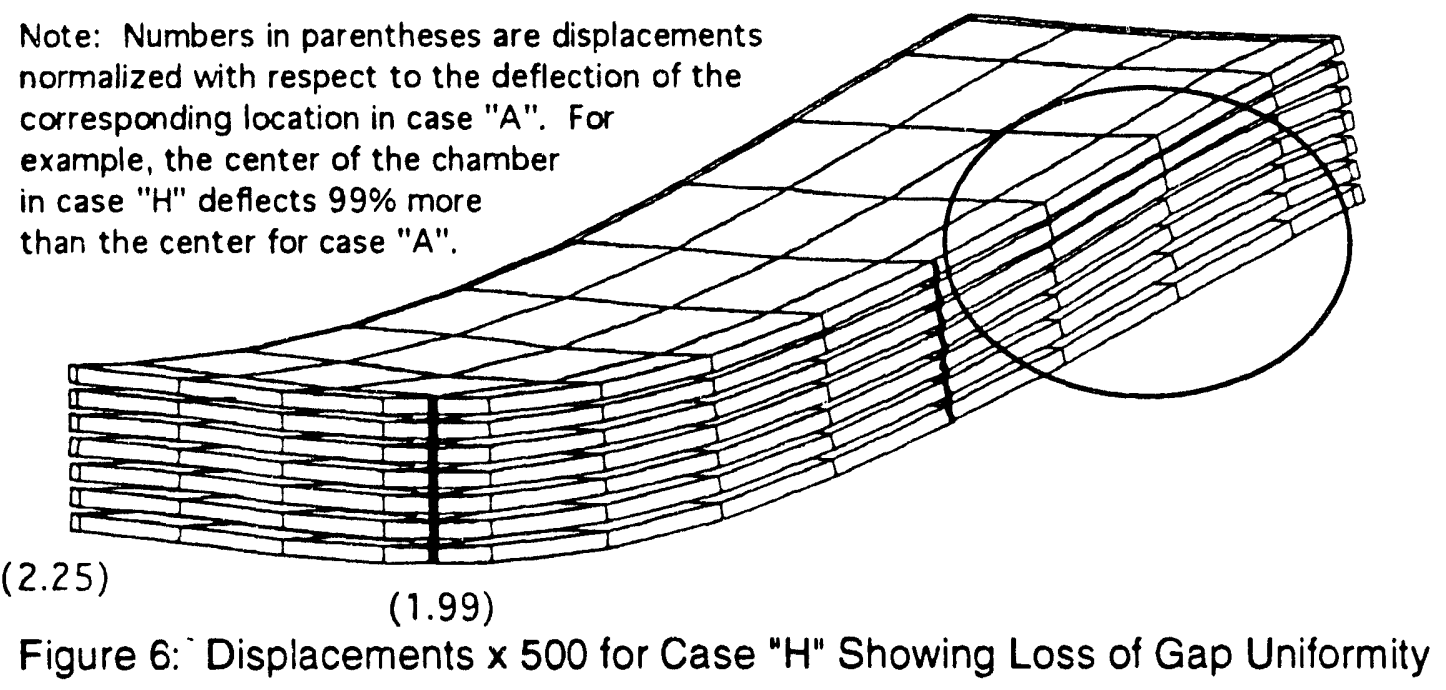

Fig. 7 illustrates the forces and moments that cause these panel curvatures.
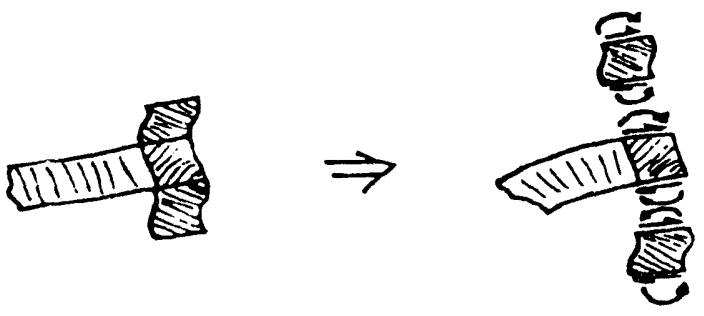

Figure 7: Moments and Shear Forces In End-Region Gap Frame 
The ends of the panels near the supports must resist moments and shear forces. This warps the panels locally and degrades gap spacing. The degradation is not visible in case "B" in Fig. 8 that has a continuous glass-fiber filled epoxy gap frame and honeycomb edge filler.

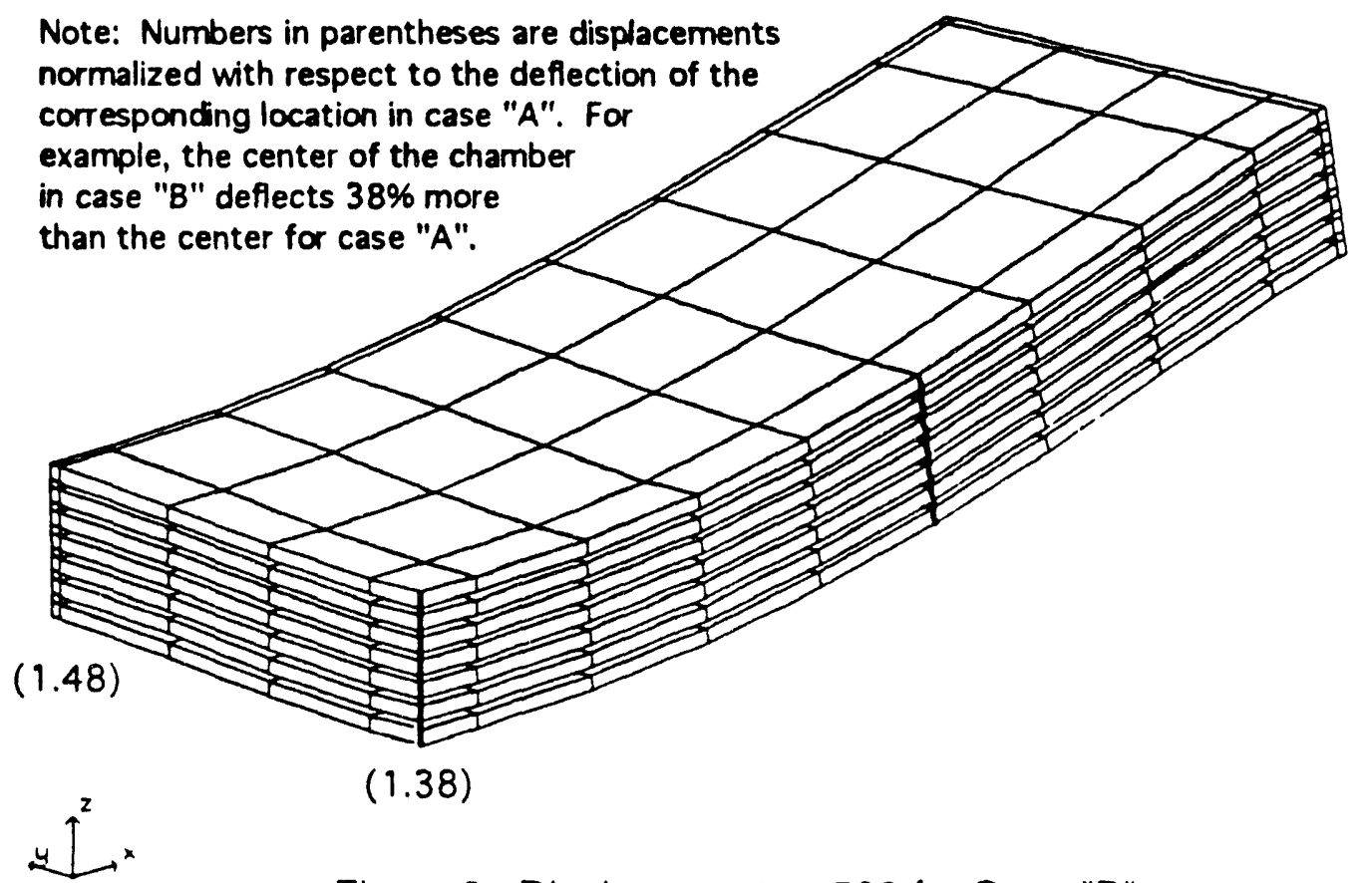

Figure 8: Displacements $\times 500$ for Case "B"

The degradation in gap spacing is visible on the right in Fig. 9 for case " $J$ " with deflections magnified 500 times.

Note: Numbers in parentheses are displacements normalized with respect to the deflection of the corresponding location in case "A". For example, the center of the chamber in case " $\mathrm{J}$ " deflects $3 \%$ more than the center for case "A".

(1.04)

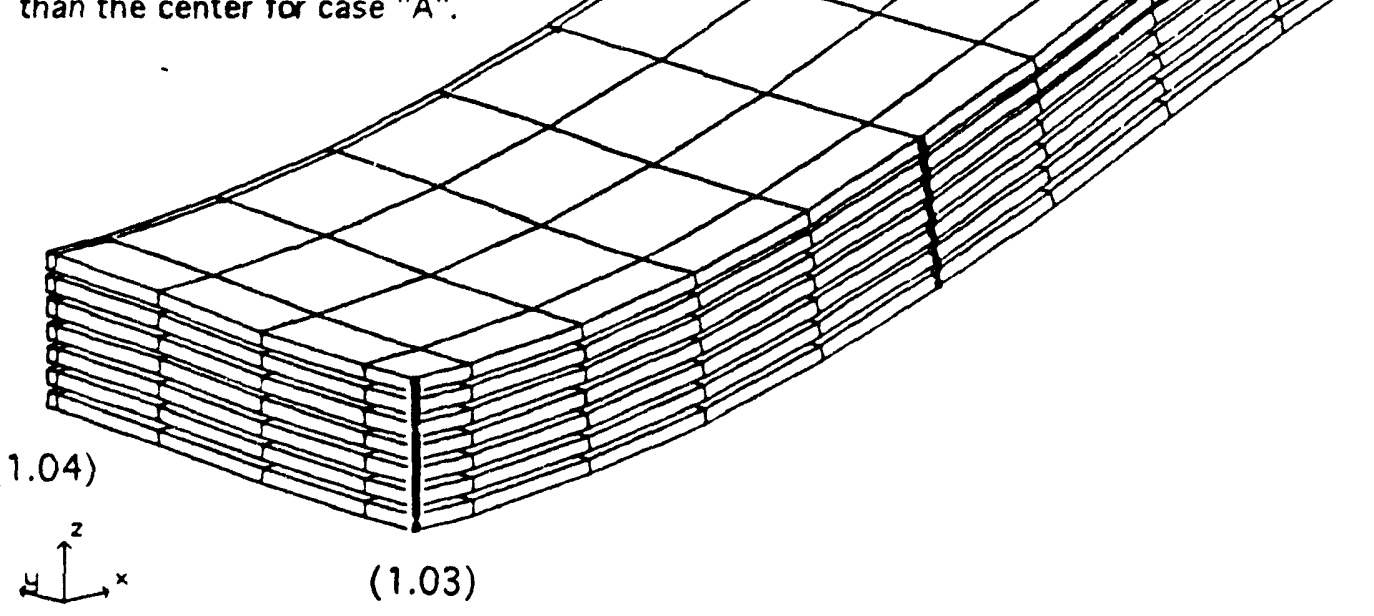

Figure 9: Displacements $\times 500$ for Case "J" 
The numbers in parentheses are the normalized deflections at those locations. For instance, in Fig. 9 the center of the long edge deflects 1.04 times more than that location in case " $A$ ". The discretepost design in case " $\mathrm{J}$ " has acceptable total deflection, but contains high stresses as discussed later in section 8 .

The magnitude of the gap-spacing error observed in Fig. 9 for case "J" exceeds 15 microns. 7 his side effect of shear deformation is a potential problem and merits additional evaluation. Discretepost designs such as cases " $\mathrm{H}$ ", "I", and " $\mathrm{J}$ " require the highest modulus gap frame because there is less shear area available to carry the load. The local shear load on individual posts requires that $a$ honeycomb edge filler be used between the discrete-post locations. Local stresses around posts will be subject to stress concentrations of 3.0 based on handbook estimates.

\section{Continuous Gap Frame Details}

The comparison analyses in this paper use a continuous gap frame $15 \mathrm{~mm}$ wide along the chamber sides and ends. Fig. 10 shows an isometric view of a continuous gap frame.

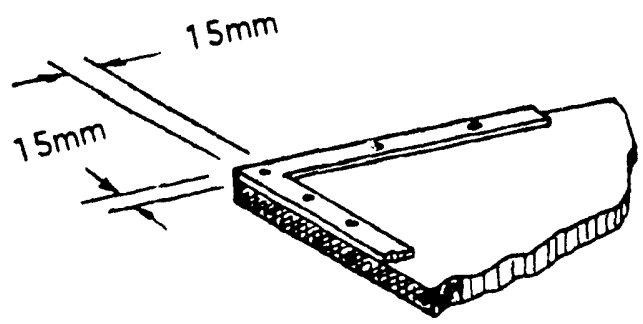

Figure 10: Isometric View of Continuous Gap Frame

The widest allowable "discrete post" that can be accommodated due to electronics as configured in Fig. 14 is $15 \mathrm{~mm}$. We use a $15 \mathrm{~mm}$ value for all gap frame' in this analysis in order to provide a fair basis for stiffness comparison.

\section{Discrete-Post Gap Frame Details}

The sketch shown in Fig. 11 and the electronics layout in Fig. 14 define a discrete-post gap frame design incorporating 48 perimeter bolts per chamber.

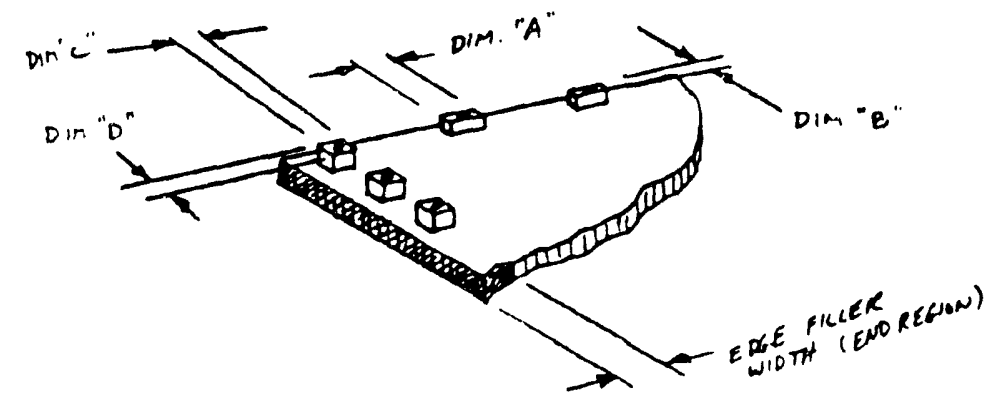

Figure 11: Isometric View of Discrete-Post Gap Frame 
The electronics layout dictates the allowable positions for the discrete posts. The resulting design is slightly shorter than a TDR outer superlayer barrel chamber.

Fig. 4 shows the bolt pattern and Fig. 12 shows a stack of panels in cross section.

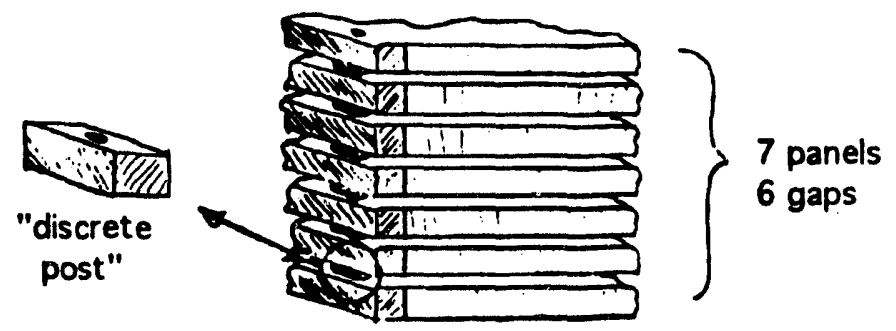

Figure 12: Cross Section of Stack of Panels With Post

Fig. 13 shows how discrete posts are always assumed to be solid through the entire chamber thickness. In the context of the discrete-post gap frame designs listed in Table 3, edge filler refers to the perimeter zone between the posts.

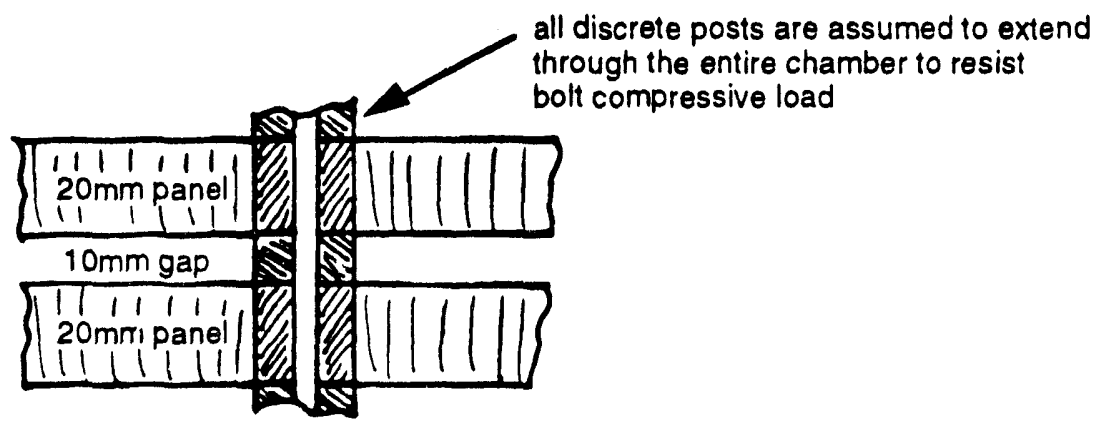

Figure 13: Cross Section of a Discrete Post

The following discrete-post design constraints are derived from conversations between Coleman Johnson, Anatoly Gordeev, and the authors:

- Discrete posts along the perimeter of the chamber are -

- Internal to the pressurized gas region;

- Dimensioned such that they do not exceed $15 \mathrm{~mm}$ in width (the distance between the "wire fixation bar" and the "sealing bar" in Fig. 15;

- Collocated with electronics components in the $15 \mathrm{~mm}$-wide zone shown in Fig. 14; and

- Limited in cross section by area not already occupied by electronics.

- There are eight evenly-spaced discrete posts along the short edges of the chamber. Provision for relocation based on chamber end region electronics exists.

- The resulting chamber design has eight wire readout connectors along the long edge, and a width that is consistent with the outer superlayer. 
A plausible electronics layout for an outer superlayer barrel chamber is shown in Fig. 14. Four $15 \mathrm{~mm}-$ by $-60 \mathrm{~mm}$ discrete posts are visible.

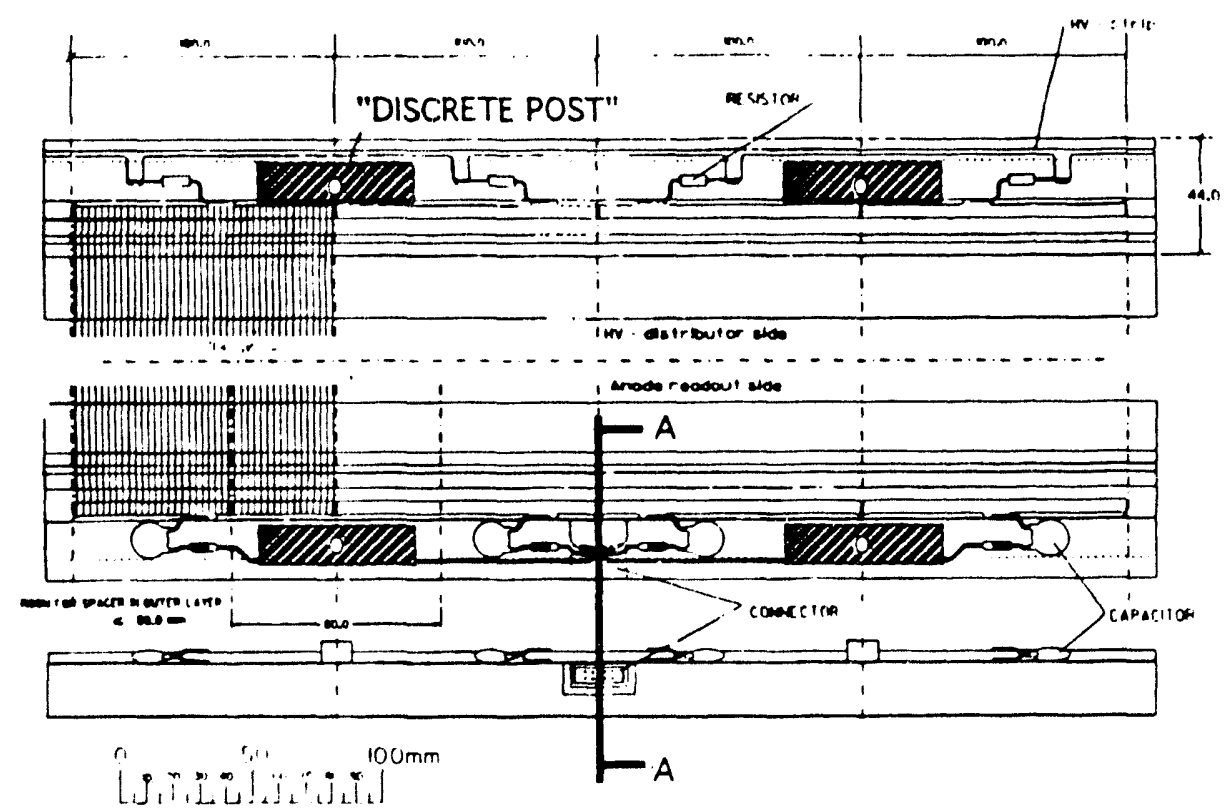

Figure 14: Layout of Perimeter Electronics for Outer Superlayer CSC

Cross section "A-A" through an edge connector is shown in Fig. 15. The discrete post is seen in profile behind the capacitor.

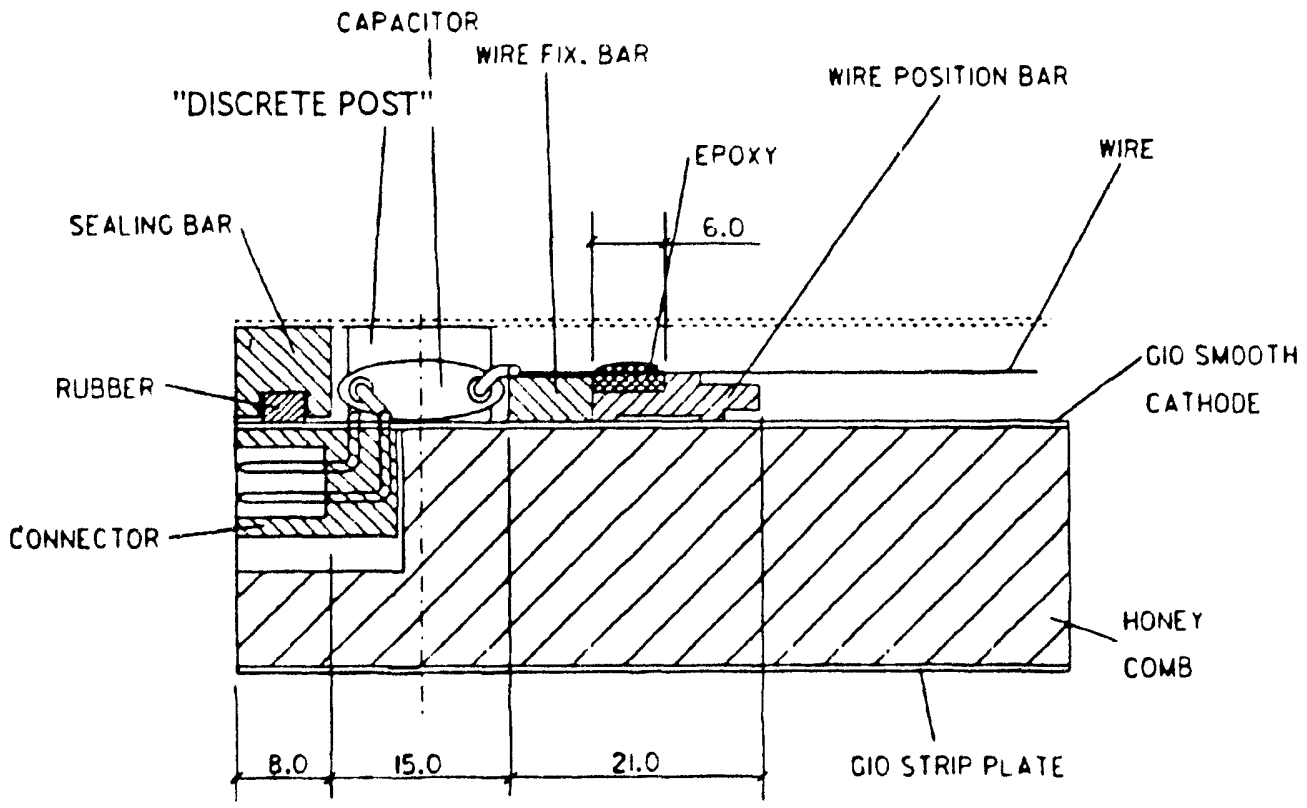

Figure 15: Cross Section "A-A" Through Edge Connector

The coexistence of gap frame material and electronic components in the same perimeter strip limits the possible size and location of the discrete posts. Assuming that the capacitors and wiring shown in Figs. 14 and 15 do not require more space than shown, $15 \mathrm{~mm} \times 60 \mathrm{~mm}$ discrete posts are the 
largest that can be accommodated. They are located on $200 \mathrm{~mm}$ centers in the 48 -post design used here.

The electrical layout in Fig. 14 is for the outer superlayer only. Similar layouts would be required for all other different electronics arrangements in order to locate and dimension the discrete posts for those chambers.

\section{Loads and Stresses}

A beam with a uniformly distributed load has a shear force distribution as shown in Fig. 16.
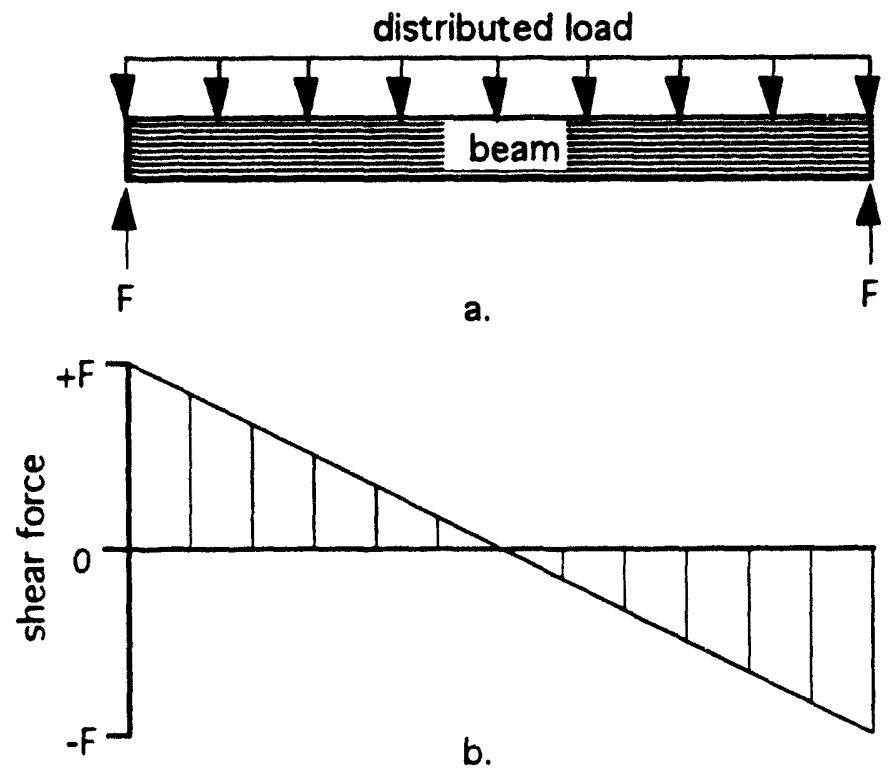

Figure 16: Load and Shear Force Distribution

We estimate the maximum stress in a continuous gap frame by assuming that the chamber weight produces a shear stress that is distributed over the gap frame vertical shear area, and a normal stress that is due to chamber overall hending. Using a chamber weight of $180 \mathrm{~kg}(400 \mathrm{lb})$ and a continuous $15 \mathrm{~mm}$-wide gap frame the maximum shear stress is $0.15 \mathrm{MPa}(22 \mathrm{psi})$ and the normal stress is $0.09 \mathrm{MPa}$ (13psi). The maximum combined stress of $0.18 \mathrm{MPa}$ (26psi) occurs near the chamber support points and diminishes to zero at the centroid of the chamber midway between the supports as seen in Fig. 16. The gravity vector is assumed to be normal to the panels for this calculation.

We estimate the maximum stress in a discrete-post gap frame by calculating the shear load carried by each post, applying this load to the post in the form of a shear force couple and moments (as shown in Fig. 7), calculating the combined stress at the post ends, and applying a stress concentration factor. Stress concentrations occur at the small-radius fillets at the ends of the discrete posts. Using a chamber mass of $180 \mathrm{~kg}(400 \mathrm{lb})$ and a stress concentration factor of 3.0 (estimate based on handbook values for similar geometries) the maximum combined stress (bending plus shear) in a $15 \mathrm{~mm} \times 60 \mathrm{~mm}$ discrete post is $5.38 \mathrm{MPa}(780 \mathrm{psi})$. This occurs at the fillets in the discrete posts near the chamber ends. 
The discrete-post-gap-frame stress is 30-times higher than a comparable continuous-gap-frame stress because of three factors:

1. the reduced shear area

2. the creation of a large bending stress

3. the introduction of a stress concentration.

Chamber gap frames should at least be continuous in the vicinity of the chamber ends where support points are located and shear forces are highest.

\section{Practical Considerations}

A discrete-post design that has posts and electrical circuitry located in the same zone (collocated design) ties the hands of chamber structural and electrical designers. No allowance is made in the collocated discrete-post concept for larger capacitors, changes in circuit trace locations, or longer continuous gap frame segments.. Also, the stiffest discrete-post design evaluated is not structurally adequate in the corners near support locations

Locating the gap frame outside of the electrical circuitry zone adds $15 \mathrm{~mm}$ to the perimeter of the chamber (each side). This material is made up of sandwich panel skins and honeycomb which accounts for about $2 \%$ to the chamber mass. This also possibly allows for a discontinuous gapframe to be used where stresses are low. The size of discrete posts could then be optimized based on the local shear stress, and an optimization can proceed unconstrained by the electronics layout details. The mass savings may however he small and not worth the detail design effort.

Many ultra-low density epoxies are only available in pre-cast blocks that must be machined and pieced into larger assemblies. This introduces additional adhesive bond lines that may be undesirable and may increase fabrication labor requirements.

The finite element analyses in this report assume a non-slip linkage between all panels in the gap frame region. In terms of chamber frame design, this "bond" between panels must be achieved by some combination of the following methods:

- friction at part interfaces that is developed and maintained by bolt pre-loads

- direct shear into perimeter bolts (the "Leggo block" effect)

- adhesive

\section{Design Recommendations}

The chamber perimeter design recommended here is structurally efficient and lends itself to further mass reduction. An optimal chamber design is one which minimizes muon scattering (mass effects), shear deformations, gravity sag. stress levels, and complexity. In other words, each component is designed to perform its structural function using the least amount of the highesi radiation-length materials.

Fig. 17 shows a cross section of the recommended chamber edge design. It possesses the following desirable characteristics:

- Edge bolts are located outside of the perimeter electronics pattern. This allows the number and spacing of bolts to be dictated by structural necessity only. (Locally discontinuous 
gap-frame designs that reduce material in the low-stress regions can be considered in the future, independent of any electronics layout details.)

- Edge bolts are located outside of the chamber gas seal. This eliminates the need for gas seals on all of the bolt ends.

- Edge bolts are threaded rods or tubes. The length and diameter of threaded rods or tubes are chosen based on the minimum required to perform the clamping function. Washers at the ends reduce local compressive stress.

- The gap frame is continuous. This eliminates the secondary bending stresses, gap spacing degradation, and stress concentrations caused by discrete posts.

- The gap frame material is glass-fiber filled epoxy. This is a castable material that has isotropic mechanical properties and is an electrical insulator.

- The core edge filler is continuous. The width can be minimized in combination with future evaluations of higher shear-modulus core materials.

- The core edge filler material is either carbon-fiber filled or glass-fiber filled epoxy. Either choice provides low total chamber displacement.

- Materials with high modulus-to-density ratios and high modulus values are used for loadcarrying components. This reduces the volume of material in a component and in all other components that must be attached to it.

- Ultra-low density materials are used for lightly-loaded components. The wire fixation bars and wire position bars are to be made from the lightest competent material.

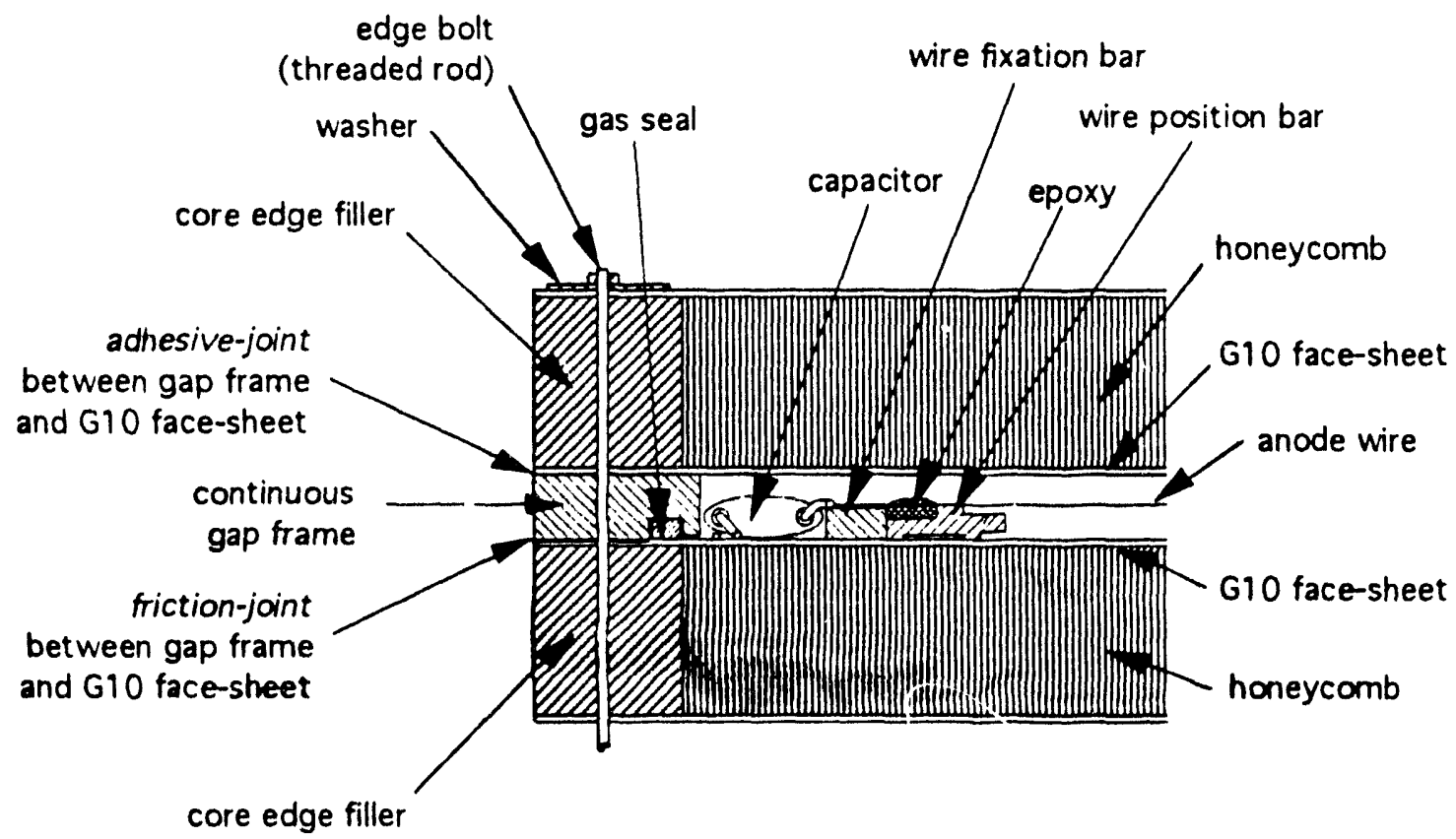

Figure 17: Cross Section of Recommended Edge Design 


\section{Further Design and Analysis Tasks}

The next paper in this series will illustrate a "generic" engineering design implementing the recommendations set forth here. This will be used for the next phase of chamber optimization.

Other recommended future tasks include the following:

- Produce a design for the chamber perimeter bolted connection that provides the non-slip bond assumed in analyses with the least added connector mass (considering threaded tubes and alternate patterns).

- Confirm radiation length and mechanical property values for all materials of interest.

- Consider higher shear-modulus panel core with the goal of further reducing the mass of the sandwich pinels while maintaining stiffness.

- Evaluate a "discontinuous" gap frame in conjunction with the recommended design.

- Evaluate the effect of an external chamber stiffening techniques (metallic "cage") on chamber mass and stiffness. 

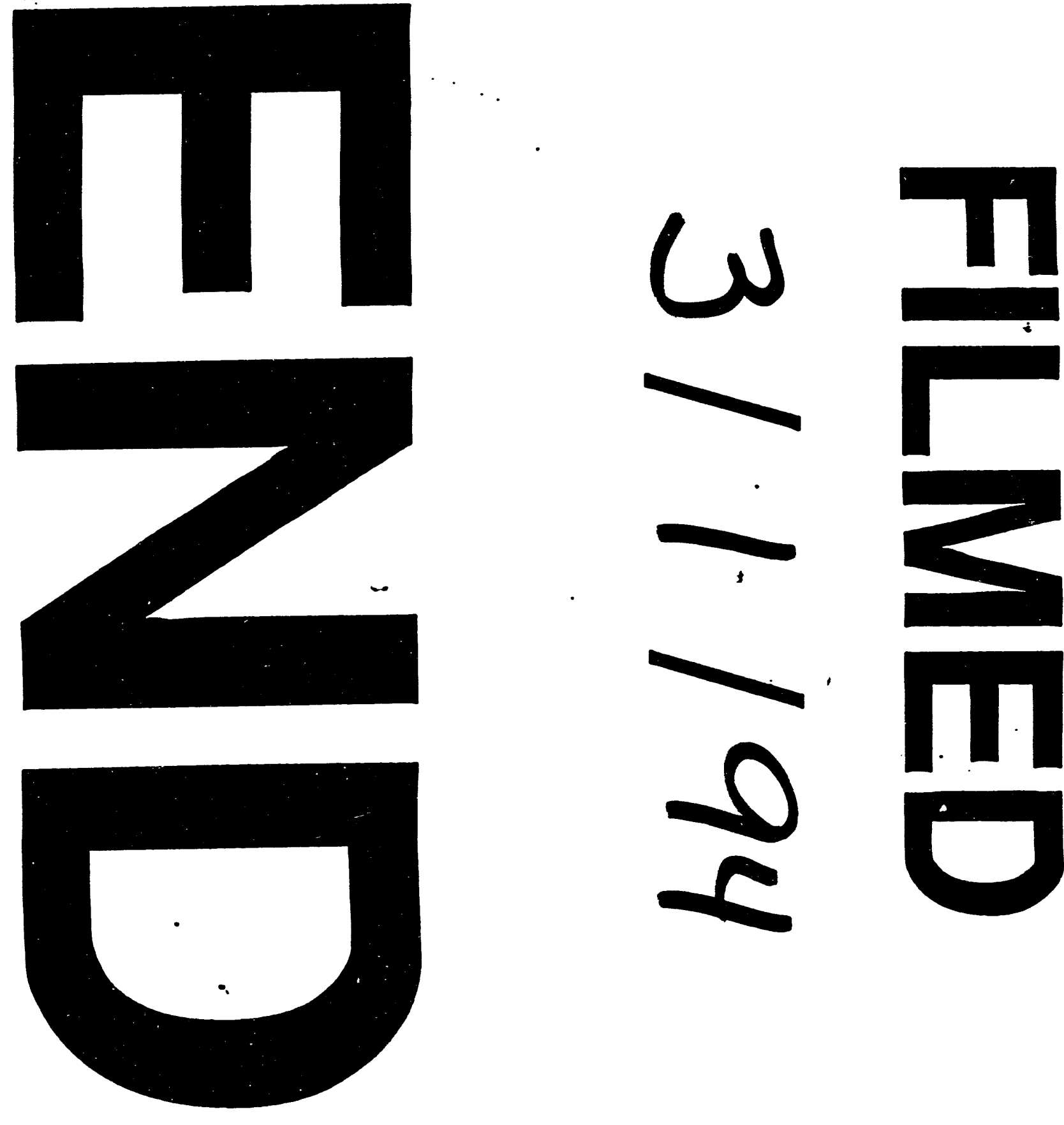

$-$
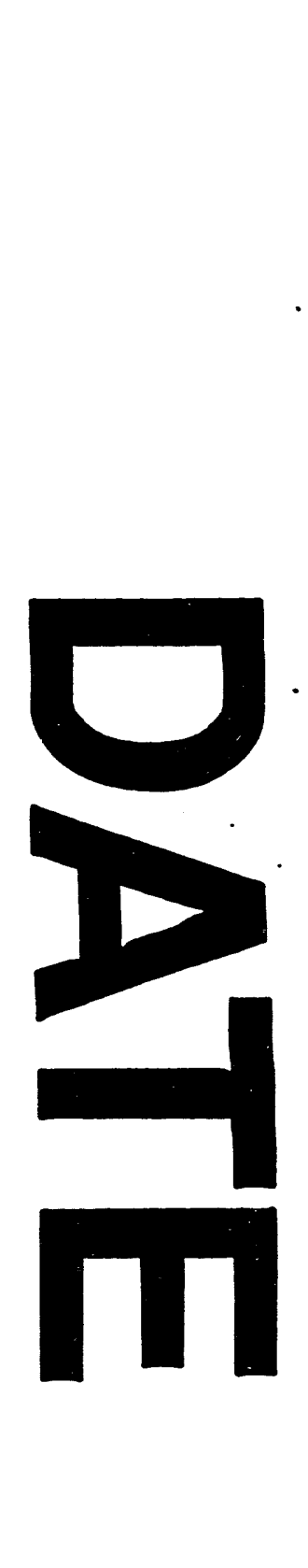

$=$ 
